\title{
Treatment of osteomyelitis with antibiotic-soaked porous glass ceramic
}

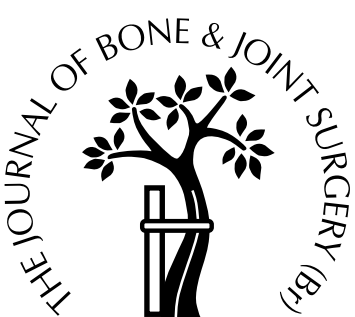

\author{
K. Kawanabe, Y. Okada, Y. Matsusue, H. Iida, T. Nakamura \\ From the University of Kyoto, Japan
}

$\mathbf{W}$ e have developed a new drug delivery system using porous apatite-wollastonite glass ceramic (A-W GC) to treat osteomyelitis. A-W GC (porosity, $\mathbf{7 0 \%}$ and $20 \%$ to $30 \%$ ), or porous hydroxyapatite (HA) blocks (porosity $35 \%$ to $48 \%$ ) used as controls, were soaked in mixtures of two antibiotics, isepamicin sulphate (ISP) and cefmetazole (CMZ) under high vacuum.

We evaluated the release concentrations of the antibiotics from the blocks. The bactericidal concentration of ISP from A-W GC was maintained for more than 42 days, but that from $\mathrm{HA}$ decreased to below the detection limit after 28 days. The concentrations of $\mathrm{CMZ}$ from both materials were lower than those of ISP. An in vivo study using rabbit femora showed that an osseous concentration of ISP was maintained at eight weeks after implantation. Osteoconduction of the A-W GC block was good.

Four patients with infected hip arthroplasties and one with osteomyelitis of the tibia have been treated with the new delivery system with excellent results.

J Bone Joint Surg [Br] 1998;80-B:527-30. Received 24 November 1997; Accepted after revision 8 January 1998

The surgical treatment of chronic osteomyelitis often produces large bone defects which should be filled to reduce recurrence. Various antibiotic carrier systems have been developed, particularly antibiotic-impregnated polymethylmethacrylate (PMMA) beads which are widely used. When such beads are used for chronic osteomyelitis, a

K. Kawanabe, MD, Assistant Professor

Y. Okada, MD, Orthopaedic Surgeon

Y. Matsusue, MD, Lecturer

H. Iida, MD, Associate Professor

T. Nakamura, Chairman and Professor of Orthopaedics

Department of Orthopaedic Surgery, Faculty of Medicine, Kyoto Uni-

versity, 54 Shogoin Kawahara-cho, Sakyo-ku, Kyoto 606-01, Japan.

Correspondence should be sent to Professor T. Nakamura.

(C)1998 British Editorial Society of Bone and Joint Surgery 0301-620X/98/38576\$2.00

VOL. 80-B, No. 3, MAY 1998 subsequent removal operation is required. Recently, drug delivery systems (DDSs) using resorbable materials such as collagen, ${ }^{3}$ fibrinogen ${ }^{4}$ and polylactic acid ${ }^{5}$ have been developed. These do not require removal, but do not replace bone grafting.

We have developed a new DDS using an antibioticsoaked porous A-W glass ceramic (GC) block which has previously been shown to form a chemical bond with living bone and to have a mechanical strength almost equal to that of cancellous bone. ${ }^{6}$

\section{Materials and Methods}

In vitro study. Two types of porous A-W GC (Nippon Electric Glass Co, Ltd, Otsu, Japan) were made into $8 \mathrm{~mm}^{3}$ blocks. They had a porosity of $70 \%$ (A-W GC 70) and $20 \%$ to $30 \%$ (A-W GC 20-30) and pore sizes of $200 \mu \mathrm{m}$ and 10 to $50 \mu \mathrm{m}$, respectively. The chemical composition of $\mathrm{A}-\mathrm{W}$ $\mathrm{GC}$ in terms of weight percentage is $\mathrm{MgO} 4.6, \mathrm{CaO} 44.9$, $\mathrm{SiO}_{2} 34.2$ and $\mathrm{CaF}_{2}$ 0.5. It contains oxyfluorapatite and $\beta$-wollastonite. Apatite accounts for approximately $35 \%$ of the weight, wollastonite for $40 \%$ and glass for $25 \%$. The method of synthesis has previously been reported by Kokubo et al. ${ }^{7}$ Porous hydroxyapatite (HA) blocks of the same size (porosity, $35 \%$ to $48 \%$; pore size, 50 to $300 \mu \mathrm{m}$; Sumitomo Pharmaceutical Co, Ltd, Tokyo Japan) were used as controls. The compressive strength of A-W GC 70 is $20 \mathrm{MPa}$, that of $\mathrm{A}-\mathrm{W}$ GC $20-30$ is $236 \mathrm{MPa}$ and that of $\mathrm{HA}$ is 45 to $70 \mathrm{MPa}$.

We used two antibiotics, isepamicin sulphate (ISP; Asahi Chemical Industry Co, Ltd, Osaka, Japan) and cefmetazole (CMZ; Sankyo Co, Ltd, Tokyo, Japan). The minimum inhibitory concentration against Staphylococcus aureus was $0.39 \mu \mathrm{g} / \mathrm{g}$ for ISP and $1.56 \mu \mathrm{g} / \mathrm{g}$ for CMZ.

The three types of porous ceramic block were placed in a bone cement mixer (Mixevac II High Vacuum System; Stryker, Michigan) into which solutions of $100 \mathrm{mg} / \mathrm{ml}$ of ISP or CMZ were poured until all the blocks were covered. A vacuum of $500 \mathrm{mmHg}$ was sustained for 10 minutes. To evaluate the elution ability of the porous blocks, each block was placed in a test tube $(15 \mathrm{ml})$, covered with $3 \mathrm{ml}$ of phosphate-buffered saline (PBS) $(\mathrm{pH} \mathrm{7.4)}$ and stored in a thermostatic chamber at $37^{\circ} \mathrm{C}$. The PBS was replaced every two days and the preserved PBS was then frozen at $-20^{\circ} \mathrm{C}$ 


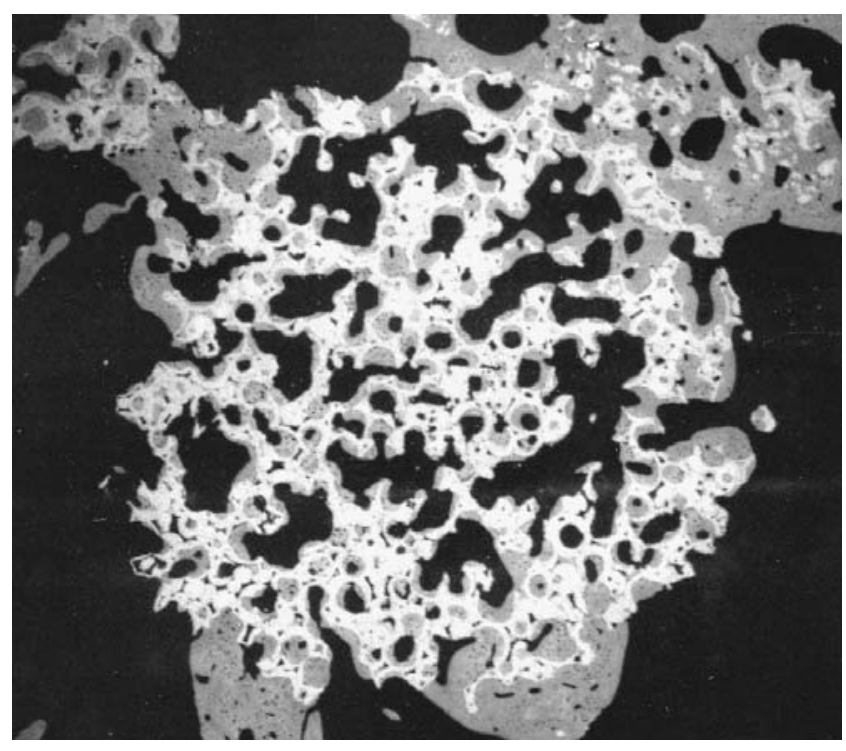

Fig. 3a

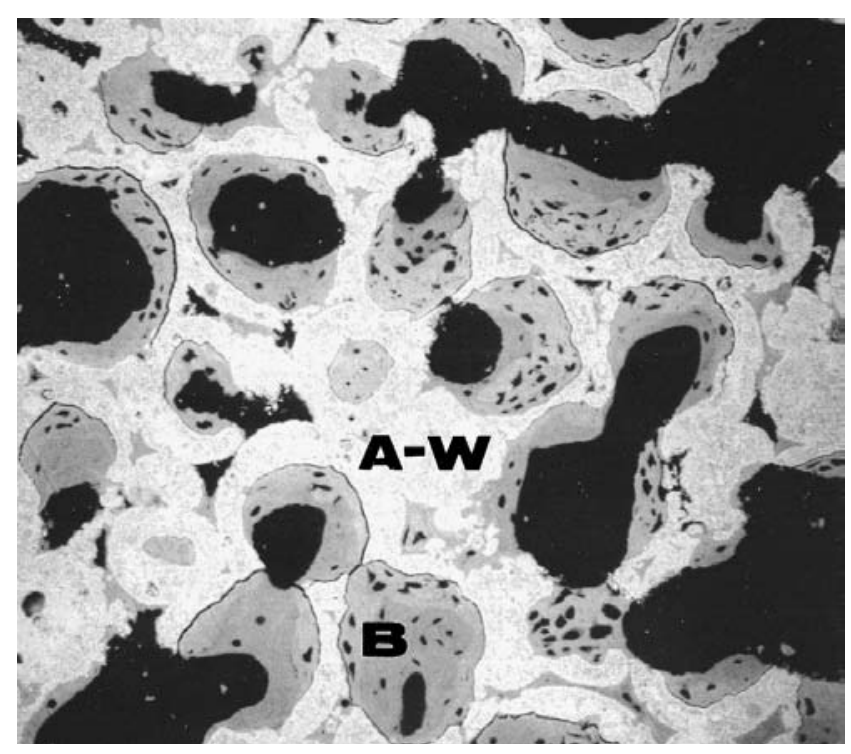

Fig. 3b

Scanning electron micrograph of A-W GC 70 eight weeks after implantation. New bone is formed in the centre of the block and bonded to the ceramic without any fibrous layer $((\mathrm{a}) \times 16$; (b) $\times 78$; A-W, A-W GC; B, bone $)$.

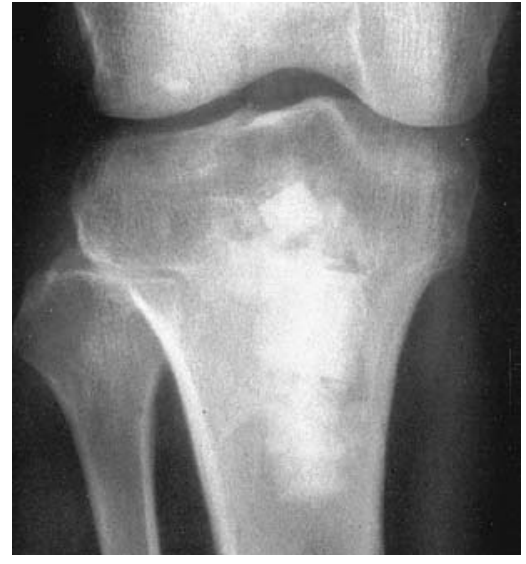

Fig. 4a

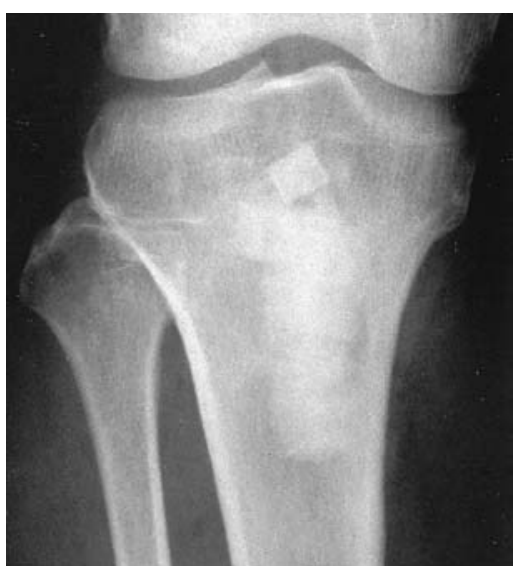

Fig. $4 b$
Radiographs of a 35-year-old man with osteomyelitis of the right tibia which recurred nine years after the primary operation. Figure $4 \mathrm{a}$ - One week after implantation of ISP-soaked porous A-W GC blocks. Figure $4 \mathrm{~b}-$ Two years after implantation. The borders between the A-W GC and bone are unclear. observed in the rabbit femora two months after implantation. SEM showed bone formation along the circumference of the pores without any intervening fibrous layer (Fig. 3). Pilot clinical study. We used these antibiotic-soaked ceramic blocks to treat five patients, four with infected arthroplasty and one with osteomyelitis of the proximal tibia. In one case, a 34-year-old-man with recurrence of osteomyelitis had curettage of the infected focus and implantation of antibiotic-soaked A-W GC 70 blocks into the defect. Two years later, the border between the bone and ceramic blocks had become almost indistinguishable (Fig. 4). In another, a 64-year-old woman with an infected total hip replacement had revision. A large actabular defect was filled with antibiotic-soaked A-W GC 70 and the new socket was fixed with PMMA bone cement and a Kerboul cross shell; there was an excellent result at 1.5 years. The other three patients all had excellent results

\section{Discussion}

The use of antibiotic-impregnated PMMA beads for the treatment of chronic osteomyelitis has been reported, ${ }^{10-13}$ but the disadvantages include low biocompatibility, a very low release ratio and possible thermal damage to the antibiotics. Hoff, Fitzgerald and Kelly ${ }^{14}$ reported that the total amount of antibiotic released from PMMA bone cement was very low, with only $5 \%$ elution of penicillin or gentamicin from the cement.

We have shown that antibiotic-soaked porous A-W GC blocks had good osteoconductive properties in clinical studies of the correction of large bone defects in the iliac crest and for the replacement of vertebrae. ${ }^{15,16}$ Ijiri et al ${ }^{6}$ have reported ectopic bone formation in porous A-W GC combined with bone morphogenic protein in rats.

Our study has shown that $90 \%$ to $100 \%$ of total ISP and 
$40 \%$ to $50 \%$ of total CMZ were released from the porous A-W GC 70 or HA blocks. Antibiotic-soaked porous ceramic blocks are thus a more efficient DDS than antibiotic-impregnated PMMA bone cement. The release ratios of the two antibiotics were quite different, possibly because ISP has a positive charge and $\mathrm{CMZ}$ a negative charge in solution. ${ }^{18}$ We speculate that the difference may be related either to their affinity for the ceramic blocks or to their solubility.

Gentamicin is used with PMMA bone cement mainly because it is resistant to the heat produced by the polymerisation of the cement but A-W GC blocks cause no thermal damage and therefore any antibiotic may be used.

There have been several reports of a DDS using porous HA and antibiotic. Shinto et $\mathrm{al}^{19}$ studied antibiotics in powder form placed in a cylindrical cavity in calcium HA blocks. Itokazu et $\mathrm{al}^{20}$ used similar porous HA blocks to ours, and soaked them with antibiotic by centrifugation. Slow release of antibiotics from HA blocks has also been reported, but our in vitro study showed that A-W GC 70 blocks absorbed and released a larger quantity of antibiotics than HA blocks, which may be related to differences in porosity and pore size. Although the porosity of A-W GC 70 is higher than that of $\mathrm{HA}$, the compression strength of A-W GC 70 is nearly equal to that of human cancellous bone. A-W GC 70 has a uniform pore size of $200 \mu \mathrm{m}$, but HA has interconnecting pores of small diameter and thus cannot absorb a large quantity of antibiotics in spite of its porosity.

Our findings suggest that a DDS with porous A-W GC 70 blocks is better than systems using PMMA beads or porous HA blocks. Our pilot clinical study showed that antibiotic-soaked A-W GC blocks appeared to be useful for the treatment of chronic osteomyelitis or infected arthroplasties with bone defects.

No benefits in any form have been received or will be received from a commercial party related directly or indirectly to the subject of this article.

\section{References}

1. Whaling H, Dingelden E, Bergmann R, Reuss K. The release of gentamicin from polymethylmethacrylate beads. J Bone Joint Surg [Br] 1978;60-B:270-5.

2. Baker AS, Greenham LW. Release of gentamicin from acrylic bone cement: elution and diffusion studies. J Bone Joint Surg [Am] 1988 ; 70-A:1551-7.
3. Ascherl R, Stemberger A, Lechner F, et al. Behandlung der chronischen osteomyelitis mit einem kollagen-antibiotika-verbund-vorläufige mitteilung. Unfallchirurgie 1986;12:125-7.

4. Zilch H, Lambiris E. The sustained release of cefotaxim from a fibrin-cefotaxim compound in treatment of osteitis. Arch Orthop Trauma Surg 1986;106:36-41.

5. Wei G, Kotoura Y, Oka M, et al. A bioabsorbable delivery system for antibiotic treatment of osteomyelitis: the use of lactic acid oligomer as a carrier. J Bone Joint Surg [Br] 1991;73-B:246-52.

6. Nakamura T, Yamamuro T, Higashi S, Kokubo T, Ito S. A new glass-ceramic for bone replacement: evaluation of its bonding to bone tissue. J Biomed Mater Res 1985;19:685-98.

7. Kokubo T, Ito S, Sakka S, Yamamuro T. Formation of a highstrength bioactive glass-ceramic in the system $\mathrm{MgO}-\mathrm{CaO}-\mathrm{SiO}_{2}-\mathrm{P}_{2} \mathrm{O}_{5}$ J Mater Sci 1986;21:536-40.

8. Yokoiyama S, Toriya M, Morohoshi T, et al. In vitro and in vivo antibacterial activity of HAPA-B, a new aminoglycoside antibiotic. Chemotherapy 1985;33(S-5):29-46.

9. Sugaware S, Tajima M, Igarashi I, et al. A new cephamycin antibiotic: in vitro and in vivo antibacterial activities. Chemotherapy 1978;26(S-5):81-98

10. Chapman MW, Hadley WK. The effect of polymethylmethacrylate and antibiotic combinations on bacterial viability: an in vitro and preliminary in vivo study. J Bone Joint Surg [Am] 1976;58-A:76-81.

11. Rosenthal AL, Rovell JM, Girard AE. Polyacrylic bone cement containing erythromycin and colistin. I. In vitro bacteriological activity and diffusion properties of erythromycin, colistin and erythromycin/colistin combination. J Int Med Res 1976;4:296-304.

12. Bayston R, Milner RDG. The sustained release of antimicrobial drugs from bone cement: an appraisal of laboratory investigation and their significance. J Bone Joint Surg [Br] 1982;64-B:460-4.

13. Kirkpatrick DK, Von Fraunhofer JA, Trachtenberg LS, Seligson D, Mangino PD. In vitro characteristics of tobramycin-PMMA beads: compressive strength and leaching. Orthopedics 1985;8:1130-3.

14. Hoff SF, Fitzgerald RH, Kelly PJ. The depot administration of penicillin $\mathrm{G}$ and gentamicin in acrylic bone cement. J Bone Joint Surg [Am] 1981;63-A:798-804.

15. Kaneda K, Asano S, Hashimoto T, Satoh S, Fujiya M. The treatment of osteoporotic-posttraumatic vertebral collapse using the Kaneda device and a bioactive ceramic vertebral prosthesis. Spine 1992;17(8 suppl):295-303.

16. Asano S, Kaneda K, Satoh S, et al. Reconstruction of an iliac crest defect with a bioactive ceramic prosthesis. Eur Spine J 1994;3: $39-44$.

17. Ijiri S, Nakamura T, Fujisawa Y, Hazama M, Komatsudani S. Ectopic bone formation in porous apatite-wollastonite-containing glass ceramic combined with bone morphogenetic protein. J Biomed Mater Res 1997;35:421-32.

18. Inui K. The Japanese Pharmacopoeia 13th Drug Information. Nippon Kouteisho Kyokai, ed. Yakugyo Jihou-sha 1996;899-902.

19. Shinto Y, Uchida A, Korkusuz F, Araki N, Ono $K$. Calcium hydroxyapatite ceramic used as a delivery system for antibiotics. J Bone Joint Surg [Br] 1992;74-B:600-4.

20. Itokazu M, Matsunaga T, Kumazawa S, Oka M. Treatment of osteomyelitis by antibiotic impregnated porous hydroxyapatite block. Clin Mater 1994;17:173-9. 